\title{
Protecting transplant recipients and live renal donors: Facing the challenges
}

\author{
Ronald B. Moore, MD, PhD, FRCSC, FACS
}

Professor Surgery \& Oncology, University of Alberta, Surgical Director of Renal Transplant, Mr. Lube Chair in Uro-Oncology, Diplomat American Board of Urology, Edmonton, AB

See related article on page 41 .

Cite as: Can Urol Assoc J 2013;7:46. http://dx.doi.org/10.5489/cuaj.241

A living organ donor goes through a very careful screening program as detailed in the article by Perlis and colleagues from the St Michaels Hospital Transplant Program. ${ }^{1}$ This screening program can be costly to both the transplant program and donor who is often not reimbursed both during workup and recovery. This may be reflected in the ratio of women to men $(2: 1)$ that are living organ donors. The decision to donate an organ can be made for many reasons. The most often stated reason is the desire to save the life or improve the health of a relative or loved one. ${ }^{2}$

Sometimes during the workup, unforeseen medical findings can be made, including medical health issues that may affect insurability and paternity issues. Thus it is important to start the consent process early so that the patient is fully informed of the potential for incidental unexpected findings. The person who gives consent to be a live organ donor should be competent, willing to donate, free from coercion, medically and psychosocially suitable, fully informed of the risks and benefits as a donor, and fully informed of the risks, benefits, and alternative treatments available to the recipient. The benefits to both donor and recipient must outweigh the risks associated with the donation and transplantation of the living donor organ. ${ }^{3}$

Unique live donor medical and psychosocial issues may mean that common criteria for eligibility may not be applicable in every circumstance. ${ }^{2,4}$ For example, not all programs decline patients with a prior kidney stone. Also unique to this donor program is the preponderance of left donor nephrectomies, with other programs reporting up to $25 \%$ of live donor transplants using the right kidney to ensure that the best kidney is retained by the donor. ${ }^{5}$ Recommending best practices for determining and communicating risks with potential donors is very important. ${ }^{2,6}$ Coming up with guidelines to solidify similar acceptance criteria for the paired exchange program will be difficult. Even a kidney considered of risk to the donor has a significant positive impact for the recipient as evident by the growing results with tumorectomized kidneys. ${ }^{7}$

Competing interests: None declared.

\section{References}

1. Perlis $\mathrm{N}$, Connelly M, Honey JR, et al. Evaluating potential live-renal donors: Causes for rejection, deferral and planned procedure type, a single-centre experience. Can Urol Assoc J 2013;7:41-5. http://dx.doi. org/10.5489/cuaj.216

2. Cockfield S, Hébert D, for The Canadian Council for Donation and Transplantation. Enhancing Living Donation: A Canadian Forum. CCDT: Edmonton, Alberta; 2006.

3. Abecassis $M$, Adams $M$, Adams $P$, et al. Consensus statement on the live organ donor. JAMA 2000;284:2919-26. http://dx.doi.org/10.1001/jama.284.22.2919

4. Barr ML, Belghiti J, Villamil FG, et al. A report of the Vancouver Forum on the care of the live organ donor: lung, liver, pancreas, and intestine data and medical guidelines. Transplantation 2006;81:1373-85. http://dx.doi.org/10.1097/01.tp.0000216825.56841.cd

5. Power RE, Preston JM, Griffin A, et al. Laparoscopic vs open living donor nephrectomy: a contemporary series from one centre. BJU Int 2006;98:133-6. http://dx.doi.org/10.1111/i.1464-410X.2006.06265.x

6. Delmonico F. A Report of the Amsterdam Forum on the Care of the Live Kidney Donor: Data and Medical Guidelines. Transplantation 2005;79:S53-66. http://dx.doi.org/10.1097/01. TP.0000157343.27949.9F

7. Brook NR, Gibbons N, Johnson DW, et al. Outcomes of transplants from patients with small renal tumours, live unrelated donors and dialysis wait-listed patients. Transpl Int 2010;23:476-83. http://dx.doi. org/10.1111/i.1432-2277.2009.01002.x

Correspondence: Dr. Ronald Moore, 2D2.16 WMC, 8440-112 Street NW, Edmonton, AB T6G 2B7; ron.moore@albertahealthservices.ca 